Scientific journal

PHYSICAL AND MATHEMATICAL EDUCATION

Has been issued since 2013 .

Науковий журнал

ФІЗИКО-МАТЕМАТИЧНА ОСВІТА

Видається з 2013.

\section{ПЕДАГОГІЧНА СТРАТЕГІЯ INQUIRY-BASED LEARNING (IBL) ДЛЯ РОЗВИТКУ МАТЕМАТИЧНОГО МИСЛЕННЯ ШКОЛЯРІВ}

\author{
Марія АСТАФ'ЄBA \\ Київський університет імені Бориса Грінченка, Україна \\ m.astafieva@kubg.edu.ua \\ https://orcid.org/0000-0002-2198-4614 \\ Катерина ГРУзДьОВА \\ Київський університет імені Бориса Грінченка, Україна \\ kihruzdova.fitu19@kubg.edu.ua \\ https://orcid.org/0000-0002-2747-3364
}

\section{PEDAGOGICAL STRATEGY INQUIRY-BASED LEARNING (IBL) FOR DEVELOPMENT OF SCHOOLCHILDREN MATHEMATICAL THINKING}

\author{
Mariia ASTAFIEVA $\square$ \\ Borys Grinchenko Kyiv University, Ukraine \\ m.astafieva@kubg.edu.ua \\ https://orcid.org/0000-0002-2198-4614 \\ Kateryna HRUZDOVA \\ Borys Grinchenko Kyiv University, Ukraine \\ kihruzdova.fitu19@kubg.edu.ua \\ https://orcid.org/0000-0002-2747-3364
}

\begin{tabular}{|c|c|}
\hline & АНОТАЦІЯ \\
\hline & 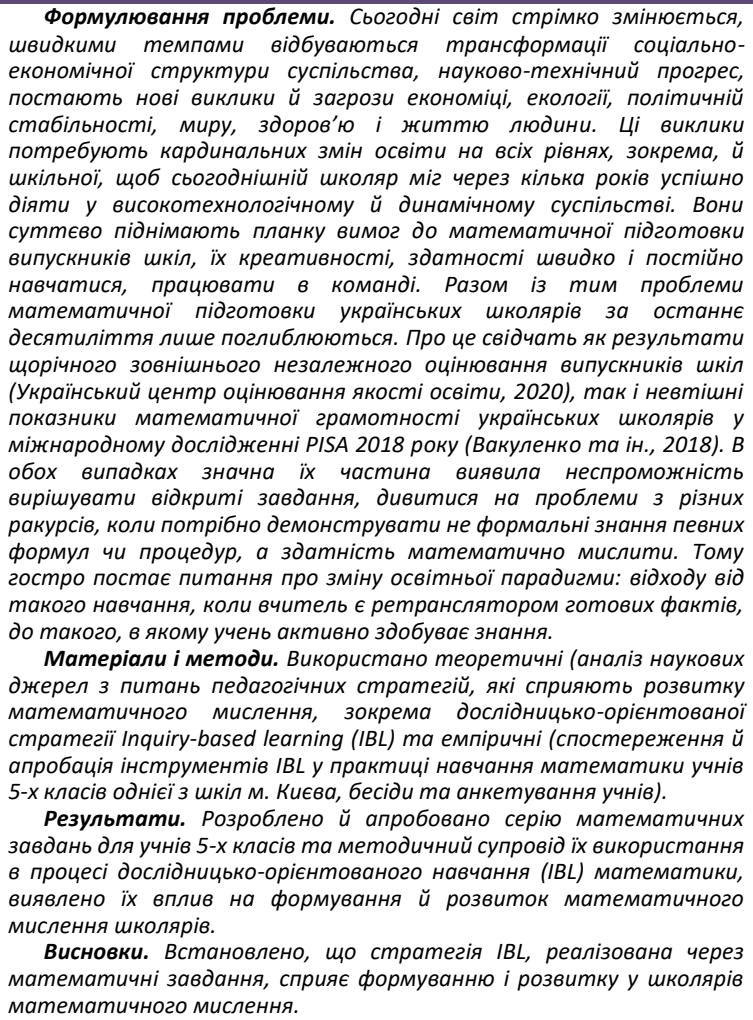 \\
\hline & $\begin{array}{l}\text { ключовІ словА: Inquiry-based Learning (IBL); дослідницько- } \\
\text { орієнтоване навчання математики; математичне мислення; } \\
\text { математичні задачі; школярі. }\end{array}$ \\
\hline
\end{tabular}

\begin{abstract}
Formulation of the problem. Today the world is changing rapidly, the socio-economic structure of society, scientific and technological progress are quickly transforming, new challenges and threats to the economy, environment, political stability, peace, health and human life arise. These challenges require radical changes in education at all levels, including school education, so that today's schoolchildren could successfully operate in a high-tech and dynamic society in a few years. They significantly raise the bar of requirements for mathematical training of school graduates, their creativity, ability to learn quickly and continuously, and work in a team. At the same time, the problems of mathematical training of Ukrainian schoolchildren have only deepened over the last decade. This is evidenced by the results of the annual external independent evaluation of school graduates (Ukrainskyi tsentr otsiniuvannia yakosti osvity, 2020), and disappointing indicators of mathematical literacy of Ukrainian schoolchildren in the international study PISA 2018 (Vakulenko at al, 2018). In both cases, many of them showed an inability to solve open problems, to look at problems from different angles, when it is necessary to demonstrate not formal knowledge of certain formulas or procedures, but the ability to think mathematically. Therefore, the question of changing the educational paradigm arises: moving away from such learning, when the teacher is a repeater of ready-made facts, to one in which the schoolchild is actively acquiring knowledge.

Materials and methods. Theoretical (analysis of scientific sources on pedagogical strategies that promote the development of mathematical thinking, including research-oriented strategy Inquiry-based Learning (IBL)) and empirical (observation and testing of IBL tools on practice of teaching mathematics to 5th graders in one of Kyiv schools, interviews and questionnaires of schoolchildren) are used.

Results. A series of mathematical tasks for 5 th grade students and methodological support for their use in the process of research-oriented learning (IBL) of mathematics has been developed and tested, their influence on the formation and development of mathematical thinking of schoolchildren has been identified.

Conclusions. It is established that the IBL strategy, implemented through mathematical tasks, promotes the formation and development of schoolchildren mathematical thinking.
\end{abstract}

KEYWORDS: Inquiry-based Learning (IBL); research-oriented learning of mathematics; mathematical thinking; mathematical problems; schoolchildren.
Для Астаф'єва М., Груздьова К. Педагогічна стратегія Inquiry-Based Learning (IBL) для розвитку математичного мислення школярів. Фізико-математична освіта, 2021 Том 32. № 6. C. 7-12. DOI: https://doi.org/10.31110/2413-1571-2021-032-6-001
цитування: Астаф'єва, М., \& Груздьова, К. (2021). Педагогічна стратегія Inquiry-Based ocsima, 32(6). 7-12. https://doi.org/10.31110/2413-1571-2021-032-6-001
Astafieva, M., \& Hruzdova, K. (2021). Pedagogical strategy Inquiry-Based Learning (IBL) for development of schoolchildren mathematical thinking. Physical and Mathematical Education, 32(6), 7-12. https://doi.org/10.31110/2413-1571-2021-032-6-001
For Astafieva, M., \& Hruzdova, K. (2021). Pedahohichna stratehiia Inquiry-Based Learning (IBL) dlia rozvytku matematychnoho myslennia shkoliariv [Pedagogical strategy Inquiry-Based Learning (IBL) for development of schoolchildren mathematical thinking]. Fizyko-matematychna osvita - Physical and Mathematical Education, 32(6), 7-12. https://doi.org/10.31110/2413-1571-2021-032-6-001 
ВСТУП

Постановка проблеми. Реформа змісту шкільної освіти в Україні покликана подолати негативні тенденції, як успадковані ще із часів СРСР, так і набуті уже в часи незалежності, і забезпечити нову їі якість, що відповідатиме сучасним запитам з боку особи та суспільства і світовим тенденціям. Суть цієї трансформації - в переході від "знаннєвого» до компетентнісного навчання, формування нового змісту освіти на базі співпраці, а не авторитаризму. Відмова від «знаннєвого» підходу у навчанні не означає, звісно, що знання не потрібні, а означає лише, що одних тільки знань замало і що знання мають бути вищої якості, добре організованими й мобільними. Державний стандарт базової середньої освіти (Державний стандарт базової середньої освіти, 2020), який буде застосовуватися з 1 вересня 2022 року, і який визначає вимоги до обов'язкових результатів навчання учнів на рівні базової середньої школи, передбачає формування 11 ключових компетентностей для життя, серед яких (на третьому місці) - математична компетентність. Математична компетентність тут трактується як «здатність розвивати і застосовувати математичні знання та методи для розв'язання широкого спектра проблем у повсякденному житті; моделювання процесів та ситуацій із застосуванням математичного апарату; усвідомлення ролі математичних знань і вмінь в особистому та суспільному житті людини» (Державний стандарт базової середньої освіти, 2020). Оскільки здатність залучати математику до вирішення реальних проблем базується на математичному мисленні, то тут ідеться саме про нього. Європейський парламент та Рада (ЄС) у своїх Рекомендаціях «Про основні компетенції для навчання протягом усього життя» (2006р.) визначили 8 ключових компетентностей XXI століття, серед яких третю позицію займає математична компетентність разом із базовими знаннями в науці й технологіях. Математична компетентність у цьому документі описується як здатність розвивати і застосовувати математичне мислення для розв'язання різних практичних проблем у повсякденних ситуаціях і контекстах, готовність простежувати причиннонаслідкові зв'язки, спроможність наводити й оцінювати аргументи, доведення (Recommendation of the European Parliament, 2006). Таким чином математичне мислення $€$ когнітивною основою і когнітивною складовою математичної компетентності. Як зазначають Хеннінсен М. та Стайн М.К., американські дослідниці в галузі математичної освіти, найкращим полем для формування і розвитку математичного мислення є математичні задачі (Henningsen \& Stein, 1997). Задачі і завдання розвивають здатність математично мислити і вільно використовувати математичні методи та прийоми. Бо «математичні задачі, якими займаються учні, визначають не лише те, що вони вивчають, але й те, як вони починають міркувати, розвивати, використовувати і розуміти математику» (Stein at al., 1996). Однак, для того, щоб задача виконала свою дидактичну функцію щодо розвитку математичного мислення учня, вона має відповідати певним вимогам, а робота з нею має бути відповідно організована. З'ясуванню питання, які це вимоги і який педагогічний супровід ефективно працює на розвиток математичного мислення учня, присвячена дана стаття.

Аналіз актуальних досліджень. Математичне мислення - це не про накопичення інформації. Математичне мислення стосується математичних процесів, а не якихось конкретних розділів математики. Особливості математичного мислення досліджуються, зокрема, в роботах (Mason at al., 2010; Астаф'єва та ін., 2013). Тут також даються цінні рекомендації, як розвивати математичне мислення у процесі розв'язування задач. Зокрема, Мейсон Д., Бертон Л., Стейсі К. умовно ділять процес розв'язання задачі чи вирішення будь-якої проблеми, дослідження ситуації на три фази: вхід (що я знаю? що я хочу? і що я можу бачити?), атака, перегляд (рефлексія) і підкреслюють, що математичне мислення розвивається й підтримується «атмосферою хороших запитань і розмірковувань» (Mason at al., 2010).

Таку атмосферу може забезпечити лише активне, дослідницько-орієнтоване навчання, на засадах конструктивізму, яке Департамент освіти Ради Європи визначає провідною методологією сучасної освіти, що допоможе сформувати ключові компетентності, необхідні для культури демократії (Competences for democratic culture). Однією 3 конструктивістських стратегій навчання $€$ Inquiry-based Learning (IBL), витоки якої прослідковуємо в працях Піаже Ж., Д’юї Д., Виготського Л., Фрейре П. Навчання через особистий досвід, активну дію і взаємодію - головний принцип конструктивізму. IBL - дослідницько-орієнтоване навчання, процес конструювання знань шляхом формулювання запитань та пошуку відповідей на них. Підхід IBL, започаткований в 60-х роках минулого століття Джозефом Швабом, активно розвивається (на всіх рівнях освіти) і досліджується в зарубіжних країнах. Свідченням цього є численні публікації, наприклад (Boaler, 1998; Goodchild at al., 2013; Lazonder \& Harmsen, 2016, Laursen \& Rasmussen, 2019; Manoli at al., 2015; Rasmussen at al., 2005; Schinck-Mikel at al., 2021) та виконання ряду проєктів. Однак в Україні лише в останні кілька років IBL входить у шкільну педагогічну практику в контексті реалізація Концепції Нової української школи (Нова українська школа, 2016). Досить сказати, що немає й адекватного україномовного перекладу терміну «Inquiry-based Learning».

B основі IBL математики лежить парадигма, в якій учнів спонукають працювати в такому ж стилі, як працюють професійні математики: спостерігати, експериментувати, помічати властивості й закономірності, задавати питання i шукати математичні, наукові способи відповідей на них, висловлювати гіпотези, робити узагальнення, інтерпретувати $\mathrm{i}$ критично оцінювати розв'язки, ефективно комунікувати у процесі пошуку, презентації, обговорення шляхів та результатів. У рамках такої парадигми учитель $\epsilon$ партнером (т'ютором, фасилітатором) спільної зі школярами діяльності. IBL потребує принципово іншої моделі організації освітнього процесу на занятті, коли викладач організовує педагогічну підтримку самостійного учіння школяра, ефективно скеровує траєкторію його пошуково-дослідницької діяльності, яка веде до отримання нового (для учня) знання.

Мета статті. Розкрити суть педагогічної стратегії Inquiry-based Learning та з'ясувати їі можливості для розвитку математичного мислення школярів.

\section{МЕТОДИ ДОСЛІДЖЕННЯ}

Роботу виконано в межах наукової теми: «Математичні методи та цифрові технологій в освіті, науці, техніці» (реєстраційний номер 0121U111924) кафедри комп'ютерних наук і математики Київського університету імені Бориса Грінченка. У процесі дослідження застосовано наступні методи: теоретичні (аналіз, синтез, систематизація та узагальнення наукової й науково-методичної літератури), емпіричні (спостереження й апробація інструментів IBL у практиці навчання математики учнів 5-х класів, бесіди та анкетування учнів). 


\section{РЕЗУЛЬТАТИ ТА ЇХ ОБГОВОРЕННЯ}

Згідно із (Zion \& Mendelovici, 2012) розрізняють три рівні організації IBL учнів на шляху до нового знання: структурований, керований та відкритий Inquiry. В реалізації IBL математики діяльність учителя та учнів на кожному з них можна характеризувати так.

Рівень І. Структурований Inquiry

Учитель формулює дослідницьке запитання (проблему, постановку задачі), коротко описує процедуру (ідею розв'язання), а учні, реалізуючи пропоновану процедуру чи ідею, приходять до відповіді (отримують результат). Етапи розв'язання, проміжні висновки чи результати, пояснюють і аргументують.

Рівень II. Керований Inquiry

Учитель формулює лише дослідницьке запитання чи задачу. Учні самостійно аналізують (відома задача чи нова), формулюють гіпотези щодо ідеї розв'язання чи результату, обирають спосіб, метод, процедуру, інструменти, які допоможуть знайти відповідь на поставлене запитання, презентують і обґрунтовують свій вибір та отриманий результат, формулюють певні висновки (чи розв'язок єдиний, чи чутливий до незначних змін параметрів, чи має цікаві частинні випадки; чи обраний метод раціональний, у чому його «плюси» і «мінуси», які можливі інші способи розв'язання).

Рівень III. Відкритий Inquiry

Учні самостійно формулюють дослідницьке запитання чи задачу, шукають спосіб дослідження чи розв'язання, розробляють і реалізують відповідну процедуру, обирають необхідні інструменти презентують свої результати та висновки. Учитель, у залежності від ситуації, виступає у ролі консультанта, партнера, члена команди, тьютора, фасилітатора чи опонента.

У залежності від рівня готовності учнів та попереднього їх досвіду пошуково-дослідницької діяльності, учитель реалізовує той чи інший рівень Inquiry. Очевидно, що починати слід із першого-другого рівнів, поступово переходячи до третього рівня, на якому дослідницька робота учнів найбільш повно повторює роботу науковців, хіба що на прикладі розв'язання простіших (для науковця, але не для учня) задач.

Не кожна задача має потенціал розвивати математичне мислення. Щоб задача розвивала математичне мислення, вона має бути для учня справжньою науковою проблемою, їі розв'язання - пошуком і дослідженням, а отриманий результат, навіть найменший - цілим математичним відкриттям. Бо, як зазначає видатний математик і педагог Пойа Д., «процес розв'язання задачі являє собою пошук виходу зі скрутної ситуації або способу обійти перешкоду, - це процес досягнення мети, яка спочатку не видається досяжною» (Пойа, 1970, С. 13). У статті (Астаф'єва, 2018) обґрунтовано, що задачі на доведення, геометричні задачі на побудову, т. зв. «цікаві» задачі та задачі з практичним змістом тренують мислення, сприяють інтелектуальному розвитку, формують дослідницькі навички, здатність до рефлексії, виховують математичну культуру.

У нашому дослідженні ми оцінювали «розвивальний» потенціал задачі не з точки зору її змісту, а з позицій:

1) характеристики самої задачі (чи передбачає вона різні способи розв'язання, чи є можливості для пояснення, обґрунтування виконуваних дій та процедур);

2) когнітивні вимоги задачі (вони можуть варіюватися від використання формул, виконання процедур і алгоритмів, без пояснень і обгрунтувань чи з ними, до використання стратегій, типових для математика, таких як спостереження, припущення, обґрунтування, інтерпретація тощо).

Наша практика показала, що, характеристика самої задачі, зазвичай, залишається незмінною від початку до завершення процесу розв'язання. Натомість когнітивні вимоги задач високого рівня мали тенденцію до зниження. Це природно, оскільки задачі високого рівня є складнішими, потребують більше часу на їх виконання і тому більш чутливі до різних факторів, які можуть привести до зниження залученості учнів та їх пізнавальної активності, а також до менш вимогливих мисленнєвих процесів. Наші спостереження дозволили виявити деякі фактори, що спричиняють зниження у процесі розв'язання рівня когнітивних вимог, а це, у свою чергу, призводить до зниження рівня пізнавальної активності учнів. Це, зокрема:

- невідповідність попередніх знань учнів вимогам задачі;

- низька мотивація;

- відсутність в учнів навичок самоконтролю;

- відсутність досвіду розв'язання задач високого рівня;

- малий ліміт часу на розв'язання.

Виявлені також фактори, що підтримують високий рівень пізнавальної активності та математичної діяльності учнів. Одним із таких факторів $є$ спонукання й заохочення учнів до самоконтролю та самоаналізу. Це вселяє в учня віру у власні сили, довіру до своєї компетентності і підтримує, таким чином, мотивацію продовжувати розв'язувати задачу. Важливим сприятливим фактором $€$ наявність достатнього часу для розв'язання задачі, щоб була можливість не поспішати (за влучним висловом Марини В'язовської «Математика - це мистецтво думати повільно»). Але найважливішим, на нашу думку, фактором $€$ забезпечення учневі такої допомоги в розв'язанні задачі, яка б не знижувала складність задачі та когнітивні вимоги до неї. Тобто проста наявність у навчальному процесі математичних задач високого рівня не веде автоматично до залучення учнів у математичну діяльність. А використання інструментів і прийомів IBL, грамотне вибудовування вчителем допомоги у вигляді системи запитань дає можливість максимально зберегти рівень когнітивних вимог задачі до кінця її розв'язання. Ілюстративним прикладом цієї тези може бути наведена нижче Задача. Вона була запропонована у п'ятому класі Спеціалізованої школи I-ІІІ ступенів №129 м. Києва з поглибленим вивченням англійської мови (вч. Катерина Груздьова)

Задача (про суму кутів трикутника). Не користуючись транспортиром, знайти суму кутів трикутника.

Учні класу поділені на малі групи (6 груп по 5 осіб). Кожна група отримує по 5 вирізаних із паперу трикутників різних кольорів і різної форми, а також по два аркуші кольорового паперу і ножиці (щоб можна було вирізати "свої» трикутники). Цим самим учитель дає приховану підказку - скористатися ножицями для знаходження суми кутів (Рис. 1). 


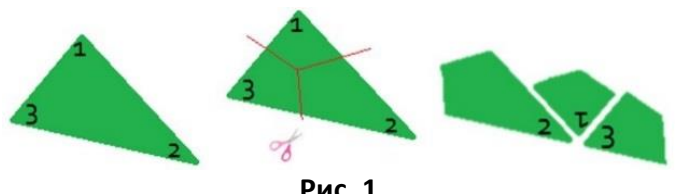

Рис. 1

Усі групи жваво обговорюють завдання, однак продуктивна ідея довго не з'являється. Була пропозиція виміряти кути лінійкою, але це не вдалося. А пропозиція виміряти транспортиром була відхилена, бо транспортир у цій задачі «заборонений» інструмент. Коли ентузіазм школярів почав згасати, учителька пропонує допомогу у вигляді одного запитання і одного завдання:

а) Запитання. «Чи можемо ми назвати / показати кут, величину якого знаємо без вимірювання»? (Учні активно відповідають: «Так, розгорнутий кут, прямий кут»; показують на навколишніх предметах прямі кути; учителька пропонує продемонструвати розгорнутий кут віялом, циркулем).

б) Завдання. Переконатися, що сума двох кутів, вирізаних із картону (завчасно заготовлені), дорівнює 90. Учні легко справляються із цим завданням, однак вчителька прагне, щоб якомога більше учнів власними руками склали із двох кутів один.

Після цього народжується ідея «скласти разом усі три кути трикутника». Але як це зробити? У двох групах вершину кута «прилаштовували» на протилежну сторону, в одній - згинати усі кути, намагаючись зібрати вершини трикутника в одній точці всередині трикутника. В одній групі вирізали окремо три кути, рівні кутам трикутника і склали їх правильно, і лише одна група скористалася ножицями і розмістила кути 1, 2 та 3, як на Рис. 1. Після цього учителька проектує Рис. 1 на екран і ті учні, які не змогли раніше виконати завдання, виконують його за зразком. Але труднощі виникали: виявилося, що скласти кути, як на рис. 1 не так то просто.

Коли «різання-складання» завершилися і учні побачили, що в кожного з них кути трикутника заповнили розгорнутий кут, вони щиро дивувалися, дехто захоплювався тим фактом, що сума кутів в кожному трикутнику дорівнює $180^{\circ}$. А один учень засумнівався: «А може Ви якісь особливі трикутники нам роздали? Може все ж $є$ трикутник, сума кутів якого не буде дорівнювати 180»? Запитання (чудове запитання! якби його ніхто не задав, учителька мала б це зробити сама), хай навіть одного учня, все ж є свідченням, що використовувана вчителькою освітня практика дає позитивн результати. Крім того це запитання дало добрий привід залучити учнів до обговорення, яке привело до висновку, що на основі 30, чи навіть 50 або 1000 прикладів можна висловити лише гіпотезу. Тут вчителька зазначила, що підмічена властивість трикутника справді має місце і довести це ми зможемо у 7 класі.

Розглянута задача корисна для розвитку математичного мислення з кількох причин:

- вона є типовим прикладом математичної проблеми, а процес її розв'язання з використанням підходу IBL нагадував роботу вченого-математика (від експерименту, спостереження - до формулювання гіпотези);

- учні мали свободу вибору шляху «від запитання до результату»;

- задача демонструє типову для математики ситуацію, коли формулювання твердження і його доведення відокремлені певним (часто досить великим) часовим проміжком.

Наведемо приклади ще двох задач для п'ятого класу, перша із яких була апробовані на уроці у тому ж 5-му класі (учителька Катерина Груздьова).

Задача (про найкоротиий маршрут). Матвій зібрався на шопінг, йому потрібно відвідати всі магазини (А, В C, D) та повернутися додому (H). Допоможіть хлопчику скласти найкоротший маршрут (Рис. 2).

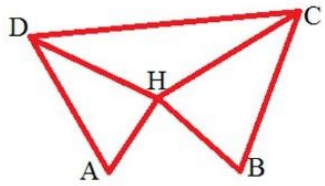

Рис. 2

Задача була запропонована п'ятикласникам при вивченні теми «Ламана». Учні називали різні маршрути (ламані), які вчителька записувала на дошці. А далі пропонували виміряти їх і обрати найкоротший. Однак учителька посилює когнітивну вимогу задачі запитанням: «Чи не могли 6 ми одразу відкинути (або й не розглядати) деякі маршрути, бо вони точно не є найкоротшими»? Замість того, щоб багаторазово виконувати одну й ту ж процедуру (вимірювання довжини ламаної), учні були поставлені в ситуацію, коли потрібно аналізувати, продукувати ідеї, висловлювати гіпотези, пояснювати й аргументувати, опонувати й слухати (й чути) відмінну від своєї точку зору, тобто виявляти високий рівень мислення та здатність до колективної роботи. В ході обговорення дійшли важливого висновку, що перша ланка маршруту має бути НА або НВ, тобто перший похід - у точку, де сходяться лише дві ланки ламаної. Після цього легко було побачити, що шуканих найкоротших маршрутів - усього два. на фермі?

Задача (Пойа). На фермі є кури і кролі. Всього у цих курей і кролів 50 голів і 140 ніг. Скільки курей і скільки кролів

Задача «добра», бо допускає різні способи розв' язання. Один із них - за допомогою рівняння чи системи рівнянь. Однак єй ариф метичний метод, цілком доступний учням $4-5$ класів. Розглянемо цей метод і наведемо можливий варіант міркувань: серію запитань, які скеровують на шлях розв'язання та гіпотетичні відповіді на них.

Запитання (гіпотетична відповідь):

- Чи можуть на фермі бути самі кури? (Ні, бо тоді ніг було б лише 100, а не 140). 
- Чи можуть на фермі бути самі кролі? (Ні, бо тоді ніг було б аж 200).

- Може варто спробувати варіант, коли курей і кролів порівну? (Так, можна. Якщо курей 25 і кролів 25, то усіх ніг буде $50+100=150$ ).

- Який висновок з цього можна зробити? (Що треба збільшувати кількість курей, при цьому кількість кролів зменшиться і, отже, сумарна кількість ніг також зменшиться).

- Як далі поступити? (Можна підбирати числа: 26 курей і, відповідно, 24 кролі і т.д., поки не дістанемо суму ніг 140).

- А чи можна уникнути перебору варіантів, тобто чи можна одразу побачити на скільки слід збільшити кількість курей і, відповідно, зменшити кількість кролів? (Так. При однаковій кількості курей і кролів число ніг на 10 перевищує дане в умові число 140, а різниця кількості ніг у кроля і курки дорівнює 2, то, значить, курей треба збільшити на 5, а кролів - на 5 зменшити. Тобто курей на фермі 25+5=30, а кролів 25-5=20).

\section{ВИСНОВКИ ТА ПЕРСПЕКТИВИ ПОДАЛЬШОГО ДОСЛІДЖЕННЯ}

Аналіз наукової літератури та власна практика показують, що стратегія IBL $\epsilon$ ефективною для розвитку математичного мислення школярів. Ї̈̈ використання, зокрема, дозволяє підтримувати високий рівень когнітивних вимог задачі в процесі їі розв'язання. Встановлено сприятливі та несприятливі фактори для тренування математичного мислення у процесі розв'язання задач.

Перспективною видається подальша робота з розробки математичних завдань, спрямованих на формування та розвиток математичного мислення і відповідного методичного забезпечення з використанням методики IBL.

\section{СПИСОК ВИКОРИСТАНИХ ДЖЕРЕЛ}

1. Астаф'єва, М. М. (2018). Роль задач у формуванні математичної компетентності школярів. Фізико-математична освіта, 3(17), 2025. https://doi.org/10.31110/2413-1571-2018-017-3-003

2. Астаф'єва, М. М., Жильцов, О. Б., \& Юртин, І. І. (2013). Математика. Вступ до спеціальності. Навчальний посібник. Навчальна книга - Богдан.

3. Вакуленко, Т. С., Горох, В. П., Ломакович, С. В., Терещенко, В. М. (уклад.), (Шумова, К. Є., перекл.). (2018). PISA: математична грамотність, Київ, УЦОЯО. https://nus.org.ua/wp-content/uploads/2018/02/Math_PISA_Framework-1.pdf

4. Державний стандарт базової середньої освіти. (2020). https://osvita.ua/legislation/Ser_osv/76886/

5. Нова українська школа. Концептуальні засади реформування середньої школи https://mon.gov.ua/storage/app/media/zagalna\%20serednya/nova-ukrainska-shkola-compressed.pdf

6. Пойа, Д. (1970). Математическое открытие. Наука.

7. Український центр оцінювання якості освіти. (2020, 21 червня) Результати з математики знО-2021: важливо знати, щоб розуміти. https://testportal.gov.ua/rezultaty-z-matematyky-zno-2021-vazhlyvo-znaty-shhob-rozumity/

8. Boaler, J. (1998). Open and closed mathematics: Student experiences and understandings. Journal for Research in Mathematics Education 29(1), 41-62.

9. Competences for democratic culture. Living together as equals in culturally diverse democratic societies. Council of Europe (2016). https://rm.coe.int/16806ccc07

10. Goodchild, S., Fuglestad, A. B., \& Jaworski, B. (2013). Critical alignment in inquiry-based practice in developing mathematics teaching. Educational Studies in Mathematics, 84(3), 393-412.

11. Henningsen, M. \& Stein, M. K. (1997). Mathematical Tasks and Student Cognition: Classroom-Based Factors that Support and Inhibit HighLevel Mathematical Thinking and Reasoning. Journal for Research in Mathematics Education, 28 (5), 524-549. https://doi.org/10.2307/749690

12. Lazonder, A.W. \& Harmsen, R. (2016) Meta-Analysis of Inquiry-Based Learning: Effects of Guidance. Review of Educational Research, 86 (3), 681-718. https://doi.org/10.3102/0034654315627366

13. Laursen, S. L., \& Rasmussen, C. (2019). I on the prize: Inquiry approaches in undergraduate mathematics. International Journal of Research in Undergraduate Mathematics Education, 5(1), 129-146.

14. Manoli, C., Pedaste, M., Mäeots, M., Siiman, L., \& Jong, T. (2015). Phases of inquiry-based learning: Definitions and the inquiry cycle. Educational Research Review, Elsevier, 14, 47-61.

15. Mason, J., Burton, L., \& Stacey, K. (2010). Thinking Mathematically. Henry Ling Ltd, Dorchester, Dorset. http://mehrmohammadi.ir/wpcontent/uploads/2019/11/Thinking-Mathematically.pdf

16. Rasmussen, C., Zandieh, M., King, K., \& Teppo, A. (2005). Advancing mathematical activity: A view of advanced mathematical thinking. Mathematical Thinking and Learning, 7, 51-73.

17. Recommendation of the European Parliament and of the Council of 18 December 2006 on key competences for lifelong learning (2006/962/EC). https://eur-lex.europa.eu/LexUriServ/LexUriServ.do?uri=OJ:L:2006:394:0010:0018:en:PDF

18. Schinck-Mikel, A., Poly, C., \& Obispo, S. L. (2021). The road to present day inquiry-based learning. http://www.inquirybasedlearning.org/whyuse-ibl

19. Stein, M. K., Grover, B. W., \& Henningsen, M. (1996). Building student capacity for mathematical thinking and reasoning: An analysis of mathematical tasks used in reform classrooms. American Educational Research Journal, 33(2), 455-488. https://doi.org/10.3102/00028312033002455

20. Zion, M., \& Mendelovici, R. (2012). Moving from structured to open inquiry: Challenges and limits. Science Education International, 23(4), 383-399.

\section{REFERENCES (TRANSLATED AND TRANSLITERATED)}

1. Astafieva, M. M. (2018). Rol zadach u formuvanni matematychnoi kompetentnosti shkoliariv [The role of problems in the formation of mathematical competence of students]. Fizyko-matematychna osvita - Physical and Mathematical Education, 3(17), 20-25. https://doi.org/10.31110/2413-1571-2018-017-3-003 (in Ukrainian).

2. Astafieva, M. M., Zhyltsov, O. B., \& Yurtyn, I. I. (2013). Matematyka. Vstup do spetsialnosti. Navchalnyi posibnyk. [Maths. Introduction to. Tutorial.] Navchalna knyha - Bohdan. (in Ukrainian).

3. Vakulenko, T. S., Horokh, V. P., Lomakovych, S. V, Tereshchenko, V. M., (Ed.). (2018). PISA: matematychna hramotnist [PISA: mathematical literacy].UCOIAO. https://nus.org.ua/wp-content/uploads/2018/02/Math_PISA_Framework-1.pdf (in Ukrainian). 
4. Derzhavnyi standart bazovoi serednoi osvity. [State standard of basic secondary education]. (2020). https://osvita.ua/legislation/Ser_osv/76886/ (in Ukrainian).

5. Nova ukrainska shkola. Kontseptualni zasady reformuvannia serednoi shkoly [New Ukrainian school. Conceptual principles of secondary school reform] (2016). https://mon.gov.ua/storage/app/media/zagalna\%20serednya/nova-ukrainska-shkola-compressed.pdf (in Ukrainian).

6. Polya, G. (1970). Matematicheskoe otkrytie. [Mathematical discovery]. Nauka. (in Russian).

7. Ukrainskyi tsentr otsiniuvannia yakosti osvity. (2020, Juni, 21) Rezultaty z matematyky ZNO-2021: vazhlyvo znaty, shchob rozumity.[Results in mathematics ZNO-2021: it is important to know to understand] https://testportal.gov.ua/rezultaty-z-matematyky-zno-2021-vazhlyvoznaty-shhob-rozumity/ (in Ukrainian)

8. Boaler, J. (1998). Open and closed mathematics: Student experiences and understandings. Journal for Research in Mathematics Education, 29(1), 41-62.

9. Competences for democratic culture. Living together as equals in culturally diverse democratic societies. Council of Europe (2016). https://rm.coe.int/16806ccc07

10. Goodchild, S., Fuglestad, A. B., \& Jaworski, B. (2013). Critical alignment in inquiry-based practice in developing mathematics teaching. Educational Studies in Mathematics, 84(3), 393-412.

11. Henningsen, M. \& Stein, M. K. (1997). Mathematical Tasks and Student Cognition: Classroom-Based Factors that Support and Inhibit HighLevel Mathematical Thinking and Reasoning. Journal for Research in Mathematics Education, 28 (5), $524-549$. https://doi.org/10.2307/749690

12. Lazonder, A.W. \& Harmsen, R. (2016) Meta-Analysis of Inquiry-Based Learning: Effects of Guidance. Review of Educational Research, 86 (3), 681-718. https://doi.org/10.3102/0034654315627366

13. Laursen, S. L., \& Rasmussen, C. (2019). I on the prize: Inquiry approaches in undergraduate mathematics. International Journal of Research in Undergraduate Mathematics Education, 5(1), 129-146.

14. Manoli, C., Pedaste, M., Mäeots, M., Siiman, L., \& Jong, T. (2015). Phases of inquiry-based learning: Definitions and the inquiry cycle. Educational Research Review, Elsevier, 14, 47-61.

15. Mason, J., Burton, L., \& Stacey, K. (2010). Thinking Mathematically. Henry Ling Ltd, Dorchester, Dorset. http://mehrmohammadi.ir/wpcontent/uploads/2019/11/Thinking-Mathematically.pdf

16. Rasmussen, C., Zandieh, M., King, K., \& Teppo, A. (2005). Advancing mathematical activity: A view of advanced mathematical thinking. Mathematical Thinking and Learning, 7, 51-73.

17. Recommendation of the European Parliament and of the Council of 18 December 2006 on key competences for lifelong learning (2006/962/EC). https://eur-lex.europa.eu/LexUriServ/LexUriServ.do?uri=OJ:L:2006:394:0010:0018:en:PDF

18. Schinck-Mikel, A., Poly, C., \& Obispo, S. L. (2021). The road to present day inquiry-based learning. http://www.inquirybasedlearning.org/whyuse-ibl

19. Stein, M. K., Grover, B. W., \& Henningsen, M. (1996). Building student capacity for mathematical thinking and reasoning: An analysis of mathematical tasks used in reform classrooms. American Educational Research Journal, 33(2), 455-488. https://doi.org/10.3102/00028312033002455

20. Zion, M., \& Mendelovici, R. (2012). Moving from structured to open inquiry: Challenges and limits. Science Education International, 23(4), 383-399.

\section{(cc) BY-NC-SA}

This work is licensed under Creative Commons Attribution-NonCommercial-ShareAlike 4.0 International License. 